\title{
Pengaruh Penerapan Sistem Informasi Akuntansi, Pengendalian Internal, Kompleksitas Tugas, dan Budaya Organisasi terhadap Kinerja Karyawan
} (Studi Kasus pada CV. Bangun Tehnik Pratama)

\author{
PUJI SETYASUNARKA \\ M. RIFKI BAKHTIAR \\ Fakultas Ekonomika dan Bisnis Universitas AKI \\ Jl Imam Bonjol No. 15-17, Pandansari, Semarang Tengah, Semarang, Jawa Tengah 50139 \\ Email: Puji.setya@unaki.ac.id
}

Diterima 28 Februari 2019; disetujui 7 Maret 2019;

\begin{abstract}
The purpose of this study was to examine the effect of accounting information system, internal control systems, task complexity, and organizational culture on employee performance of CV. Bangun Tehnik Pratama Semarang, The population of this research is all employees of CV. Bangun Tehnik Pratama Semarang, totaling 45 people. The method used in this study was census, so the sample in this study were 45 people. Based on the results of hypothesis testing the results of this study showed that: there was a positive and significant influence of accounting information system variable, internal recognition system variable, task complexity variable, and organizational culture variable on employee performance.
\end{abstract}

Keywords: Accounting information system, Internal Control Systems, Task Complexity, Organizational culture, Organizational culture.

\section{PENDAHULUAN}

Latar Belakang. Kinerja merupakan gambaran tentang pencapaian atau target, pelaksanaan program, usaha, dan kebijakan yang dilakukan untuk mewujudkan visi, misi, dan tujuan dalam kelompok atau organisasi (Mahrus dalam Alannita dan I Gusti, 2014). Dalam suatu perusahaan kinerja karyawan sangatlah mempengaruhi hasil yang akan didapat oleh perusahaan tersebut.

Banyak faktor-faktor yang mempengaruhi kinerja karyawan dalam suatu perusahaan yang sangat berpengaruh. Dalam penelitian ini ada beberapa faktor yang digunakan yaitu penerapan sistem informasi akuntansi dalam perusahaan, jalannya sistem pengendalian internal, kompleksitas tugas yang diberikan pada karyawan, dan budaya organisasi yang ada dalam perusahaan tersebut.
Sistem yang baik dianggap sebagai faktor penting dalam pencapaian kinerja yang lebih besar terutama dalam proses pengambilan keputusan. Semakin baik kualitas sistem informasi akuntansi yang meliputi: mudah digunakan, akses yang cepat, handal, fleksibel, dan aman melindungi data pengguna maka pengguna sistem akan merasa puas (Kasandra dalam Ika Listiana 2017).

Kinerja karyawan juga dapat dipengaruhi oleh sistem pengendalian internal. Sistem pengendalian internal terdiri dari kebijakan dan prosedur yang dirancang agar manajemen mendapat keyakinan yang memadai bahwa perusahaan tersebut mencapai tujuan. Dari pengertian para ahli bahwa sebuah sistem pengendalian internal digunakan untuk membantu memantau kegiatan di dalam lingkup perusahaan (Arens et al dalam Farisa, Septarina \& Siti, 2015). 
Dalam Eny, Kartika, dan Siti (2014) ada faktor lain yang mempengaruhi kinerja karyawan, salah satunya adalah kompleksitas tugas. Kompleksitas tugas merupakan tugas yang kompleks dan rumit. Kompleksitas tugas dapat membuat seorang karyawan menjadi tidak konsistensi dan tidak akuntanbilitas. Hariani, dkk dalam Dewa Made \& Ida Bagus (2016) menyatakan budaya organisasi mempunyai pengaruh yang besar pada perilaku anggota-anggotanya dalam mewujudkan strategi organisasi. Menurut Yamin dalam Dewa Made \& Ida Bagus (2016) karena budaya organisasi merupakan kebiasaan-kebiasaan yang terjadi dalam hirarki organisasi yang mewakili norma-norma perilaku dan diikuti oleh para anggota dalam organisasi.

Kinerja dapat diketahui dan diukur bilamana individu atau sekelompok karyawan telah mempunyai kriteria atau standar keberhasilan tolok ukur yang ditetapkan oleh organisasi, tanpa tujuan dan target yang ditetapkan dalam pengukuran, maka kinerja pada seseorang atau kinerja organisasi tidak mungkin dapat diketahui bila tidak ada tolok ukur keberhasilannya (Moeheriono dalam Arisni Mardikawati, 2016), Kinerja karyawan yang baik selalu memberikan kontribusi yang positif.

Tujuan Penelitian. Berdasarkan latar belakang tersebut, tujuan yang ingin dicapai dalam penelitian ini antara lain:

1. Menguji pengaruh penerapan sistem informasi akuntansi terhadap kinerja karyawan pada CV. Bangun Tehnik Pratama Semarang

2. Menguji pengaruh jalannya sistem pengendalian internal terhadap kinerja karyawan pada CV. Bangun Tehnik Pratama Semarang

3. Menguji pengaruh kompleksitas tugas terhadap kinerja karyawan pada CV. Bangun Tehnik Pratama Semarang

4. Menguji pengaruh budaya organisasi terhadap kinerja karyawan pada CV. Bangun Tehnik Pratama Semarang

\section{TINJAUAN TEORETIS}

Kinerja Karyawan. Kinerja menurut Moeheriono dalam Ika Listiana (2017). kinerja atau performance dalam hal ini merupakan gambaran mengenai tingkat pencapaian dalam pelaksanaan suatu program kegiatan atau kebijakan untuk mewujudkan sasaran, tujuan, visi dan misi organisasi yang dituangkan melalui perencanaan strategis suatu organisasi.

Menurut Robbins dalam Lastri Andayani (2016), kinerja karyawan (prestasi kerja) adalah hasil kerja secara kualitas dan kuantitas yang dicapai oleh seseorang karyawan dalam melaksanakan tugasnya sesuai dengan tanggung jawab yang diberikan kepadanya.

Kinerja karyawan tidak dapat di lihat dan diartikan hanya sekedar informasi untuk dapat dilakukannya promosi atau penetapan gaji bagi perusahaan. tetapi bagaimana perusahaan bisa memotivasi karyawan dan mengembangkan satu rencana untuk memperbaiki penurunan kinerja yang dapat dihindari. Kinerja karyawan sangat perlu karena penilaian dengan maksud untuk memberikan satu peluang yang baik. Munandar (2008), penilaian kinerja merupakan suatu proses penilaian ciri- ciri kepribadian, perilaku kerja, dan hasil kerja seseorang tenaga kerja atau karyawan (pekerja dan manajer), dimana yang dianggap sebagai penunjang unjuk hasil kerjanya, digunakan sebagai bahan pertimbangan untuk pengambilan keputusan dalam tindakan-tindakan terhadap bidang ketenagakerjaan. Suatu perusahaan melakukan penilaian kinerja berdasarkan pertimbangan bahwa perlu adanya suatu sistem evaluasi yang objektif terhadap sebuah organisasional. Dengan adanya penilaian kinerja, manajer dapat memperoleh keterangan dasar yang objektif untuk memberikan kompensasi sesuai dengan prestasi yang disumbangkan masingmasing pemegang pertanggung jawaban kepada perusahaan secara keseluruhan. Semua ini diharapkan dapat membentuk motivasi dan rangsangan kepada masing-masing bagian untuk bekerja lebih efektif dan efisien.

Sistem Informasi Akuntansi. Sistem informasi akuntansi merupakan sistem informasi fungsional yang mendasari sistem informasi fungsional yang lainnya seperti sistem informasi keuangan, sistem informasi pemasaran, sistem informasi produksi dan sistem informasi sumber daya manusia.

Menurut Mulyadi (2001) mendefinisikan, "Sistem akuntansi adalah organisasi formulir, catatan dan laporan yang dikoordinasi sedemikian rupa 
untuk menyediakan informasi keuangan yang dibutuhkan oleh manajemen guna memudahkan pengelolaan perusahaan."

Menurut Romney dan Steinbart (2015), Sistem informasi akuntansi adalah sistem yang digunakan untuk mengumpulkan, mencatat, menyimpan dan mengolah data untuk menghasilkan suatu informasi untuk pengambilan keputusan. Sistem ini meliputi orang, prosedur dan instruksi data perangkat lunak, infrastruktur teknologi informasi serta pengendalian internal dan ukuran keamanan. Menurut Gelinas dan Dull (2012), Sistem Informasi Akuntansi adalah sistem yang digunakan untuk mengumpulkan, memproses, dan melaporkan informasi yang berhubungan dengan aspek keuangan dari peristiwa bisnis.

Menurut Hall (2008), Sistem Informasi Akuntansi adalah suatu proses transaksi keuangan dan transaksi non keuangan yang mempengaruhi pemrosesan transaksi keuangan dan terdapat pemrosesan data di dalamnya.

Terdapat 3 subsystem SIA, yaitu:

1. TPS (Transaction Processing System) berupa dukungan operasi bisnis dengan sistem laporan, dokumen dan pesan untuk user dalam suatu organisasi.

2. General Ledger/Financial Reporting System (GL/FRS) yaitu berupa prosedur tradisional laporan keuangan seperti income statement, balance sheet, laporan arus kas, pajak, dan laporan lain yang tersedia.

3. Management Reporting System (MRS) yaitu berupa penyediaan informasi kepada pihak manager internal dengan tujuan laporan keuangan dan informasi yang dibutuhkan dalam pengambilan keputusan seperti biaya, laporan yang bervariasi, dan laporan pertanggung jawaban.

Dapat disimpulkan bahwa Sistem Informasi Akuntansi merupakan proses transaksi keuangan dan transaksi non keuangan yang mempengaruhi pemrosesan transaksi keuangan dan terdapat pemrosesan data di dalam nya. Yaitu berupa sistem yang digunakan untuk mengumpulkan, mengolah, dan melaporkan informasi terkait dengan aspek keuangan akan kegiatan bisnis.

Sistem Pengendalian Internal. Sistem pengendalian internal merupakan metode yang berguna bagi manajemen untuk menjaga kekayaan organisasi, meningkatkan efektivitas dan efisiensi kinerja (Anggreini, 2012). Pada umumnya, perusahaan menggunakan sistem pengendalian internal untuk mencegah terjadinya penyalahgunaan sistem dan membantu operasional perusahaan agar dapat terarah dengan baik (Chung, 2015). Sistem pengendalian internal didalamnya terdapat struktur organisasi dimana merupakan sistem yang berfungsi untuk menjaga organisasi tetap bisa bertahan dalam mencapai tujuan.

Kompleksitas Tugas. Terdapat beberapa definisi lain tentang kompleksitas tugas, antara lain yaitu kompleksitas tugas dapat didefinisikan sebagai fungsi dari tugas itu sendiri. Kompleksitas tugas merupakan tugas yang tidak terstrukstur, membingungkan, dan sulit (Sanusi dan Iskandar,2007 dalam Parjanti, dkk,2014).

Seseorang yang dihadapkan pada komplek sitas tugas yang rendah akan mengerahkan usaha yang lebih besar untuk menyelesaikan tugas tersebut, dimana usaha tersebut akan berpengaruh terhadap kinerja yang dihasilkan. Sebaliknya, kompleksitas tugas yang tinggi, menurunkan usaha seseorang dalam menyelesaikan tugas dimana hal ini berpengaruh terhadap penurunan kinerja yang dihasilkan (Parjanti, dkk 2014).

Kompleksitas tugas merupakan tugas yang tidak terstruktur, membingungkan dan sulit (Sanusi dalam Cecilia, 2007). Akuntan selalu dihadapkan dengan tugas-tugas yang kompleks, berbeda-beda dan saling terkait satu dengan yang lainnya. Beberapa tugas audit dipertimbangkan sebagai tugas dengan kompleksitas yang tinggi dan sulit, sementara yang lain mempersepsikannya sebagai tugas yang mudah. Definisi kompleksitas tugas dalam penelitian ini diartikan sebagai tugas yang kompleks, terdiri atas bagian-bagian yang berbeda dan saling terkait satu dengan yang lain.

Budaya Organisasi. Pengertian budaya organisasi pemahaman para pakar mengenai budaya organisasi sebagai kesepakatan bersama mengenai nilai-nilai kehidupan yang mengikat semua orang dalam organisasi mendasari arti penting pemahaman budaya organisasi orang-orang yang tergabung di dalamnya. Robbins and Judge (2008) Menurut Harvey dan Brown (2009) 
Menurut Budiono, dkk (2016) mendefinisikan budaya organisasi sebagai suatu sistem nilai dan kepercayaan bersama yang berinteraksi dengan orang- orang, struktur dan sistem suatu organisasi untuk menghasilkan norma-norma perilaku. Budaya organisasi merupakan pedoman berprilaku bagi orang-orang dalam perusahaan.

Kultur dalam organisasi mengacu pada sebuah sistem dimana merupakan makna bersama yang dianut oleh para anggota yang membedakan organisasi tersebut dengan organisasi lainya. Budaya organisasi merupakan pengendali dan arah dalam membentuk sikap maupun perilaku para anggota. Secara individu maupun dalam kelompok seseorang tidak akan terlepas dari apa itu budaya organisasi dan pada umumnya anggota organisasi dipengaruhi oleh beraneka ragamnya sumber daya yang ada.

Hipotesis. Berdasarkan tinjauan teoretis dan penelitian terdahulu, maka hipotesis yang diajukan dalam penelitian ini antara lain:

H1 :Penerapan Sistem informasi akuntansi berpengaruh positif dan signifikan terhadap kinerja karyawan pada CV. Bangun Tehnik Pratama Semarang.

H2 : Sistem Pengendalian Internal berpengaruh positif dan signifikan terhadap terhadap kinerja karyawan pada CV. Bangun Tehnik Pratama Semarang.

H3 :Kompleksitas Tugas berpengaruh positif dan signifikan terhadap kinerja karyawan pada CV. Bangun Tehnik Pratama Semarang.

$\mathrm{H} 4$ :Budaya Organisasi berpengaruh positif dan signifikan terhadap kinerja karyawan pada CV. Bangun Tehnik Pratama Semarang.

\section{METODE PENELITIAN}

Populasi dan Sampel. Dalam penelitian ini Populasi dan Sampel adalah karyawan CV. Bangun Tehnik Pratama Semarang yang berjumlah 45 karyawan, maka sampel yang akan diambil sebagai penelitian ini berjumlah 45 orang karyawan

Operasional Variabel. Variabel yang digunakan dalam penelitian ini terdiri dari Sistem Informasi Akuntansi(X1), Sistem Pengendalian Internal (X2), Kompleksitas Tugas (X3) dan Budaya Organisasi (X4) sebagai variabel independen, sedangkan variabel dependen yang digunakan adalah Kinerja Karyawan (Y) Konsep dan indicator yang digunakan masing-masing variabel dapat dilihat pada tabel 1.

Teknik Analisis Data. Hubungan antara Sistem Informasi Akuntansi, Sistem Pengendalian Internal, Kompleksitas Tugas, Budaya Organisasi dengan Kinerja Karyawan diukur dengan rumus sebagai berikut :

$$
\begin{array}{ll}
\mathrm{Y}=\mathrm{a}+\mathrm{b}_{1} \mathrm{X}_{1} & +\mathrm{b}_{2} \mathrm{X}_{2}+\mathrm{b}_{3} \mathrm{X}_{3}+\mathrm{b}_{4} \mathrm{X}_{4}+\mathrm{e} \\
\text { Dimana: } & \\
\mathrm{Y} & =\text { Variabel terikat } \\
\mathrm{a} & =\text { Konstanta } \\
\mathrm{b}_{1}, \mathrm{~b}_{2}, \mathrm{~b}_{3} & =\text { Koefisien garis regresi } \\
\mathrm{X}_{1}, \mathrm{X}_{2}, \mathrm{X}_{3} & =\text { Variabel bebas } \\
\mathrm{e} & =\text { Error/ variabel pengganggu }
\end{array}
$$

\section{HASIL DAN PEMBAHASAN}

Uji Validitas dan Reliabilitas. Pengujian validitas variabel pengaruh penerapan sistem informasi akuntansi, sistem pengendalian internal, kompleksitas tugas dan budaya organisasi terhadap kinerja karyawan dapat di lihat pada tabel 2, sedangkan hasil uji reliabilitas dapat dilihat pada tabel 3 .

Analisis Regresi Linier Berganda Berdasarkan tabel 4 dapat diketahui persamaan regresi yang terbentuk adalah :

$$
\begin{aligned}
Y= & -6,469+0,163 X_{1}+0,312 X_{2}+0,494 X_{3} \\
& +0,650 X_{4}
\end{aligned}
$$

Dari persamaan regresi linier berganda tersebut pada table 4 menunjukan bahwa :

1. Nilai konstanta sebesar $-6,469$ mempunyai arti jika tidak ada peningkatan variabel sistem informasi akuntansi $\left(\mathrm{X}_{1}\right)$, sistem pengendalian internal $\left(\mathrm{X}_{2}\right)$, kompleksitas tugas $\left(\mathrm{X}_{3}\right)$, budaya organisasi $\left(\mathrm{X}_{4}\right)$ maka kinerja karyawan akan menurun sebesar -6,469.

2. B1 (nilai koefisien regresi $X_{1}$ ) sebesar 0,163 mempunyai arti koefisien regresi sistem informasi akuntansi $\left(\mathrm{X}_{1}\right)$ bernilai positif yang berarti bahwa akan meningkatkan kinerja karyawan sebesar 0,163 atau $16,3 \%$.

3. B2 (nilai koefisien regresi $X_{2}$ ) sebesar 0,312 mempunyai arti koefisien regresi sistem pengendalian internal $\left(\mathrm{X}_{2}\right)$ bernilai positif yang berarti bahwa akan meningkatkan kinerja karyawan 
Tabel 1

Operasionalisasi Variabel Penelitian

\begin{tabular}{cll}
\hline Variabel & \multicolumn{1}{c}{ Konsep Variabel } & \multicolumn{1}{c}{ Indikator } \\
\hline Kinerja Karyawan $(\mathrm{Y})$ & Tingkat keberhasilan yang dicapai seseorang & 1. Kualitas Kerja \\
& dalam melaksanakan tugas yang dibandingkan & 2. Kuantitas Kerja \\
& dengan standar kerja atau kriteria yang telah & 3. Ketepatan Waktu \\
& ditetapkan. (Astuti dan Dharmidiaksa, 2014 & 4. Kehadiran \\
& dalam Ika Listiana, 2017) & 5. Kemampuan Bekerja Sama \\
& & (Sugriningsih,2015 dalam Ika \\
& & Listiana 2017)
\end{tabular}

Sistem Informasi

Akuntansi (X1)
Sistem informasi akuntansi adalah kumpulan 1. Sumber daya manusia sumber daya, seperti manusia dan peralatan, 2. Peralatan yang diatur untuk mengubah data menjadi 3. Formulir informasi(Bodnar dan Hopwood, 2000 dalam 4. Catatan Eny Parjanti, dkk, 2014). $\quad$ 5. Prosedur

6. Laporan

(Chusing (2006) dalam Fahmi Rizaldi \& Bambang Suryono 2015)
Sistem Pengendalian Inter nal (X2)

\begin{abstract}
Pengendalian internal merupakan suatu 1. Efektivitas dan efesiensi proses yang dipengaruhi oleh dewan direksi, 2. Keandalan pelaporan manajemen dan personil lainnya yang keuangan dirancang untuk memberikan keyakinan yang 3. Ketaatan pada hukum dan memadai akan tercapainya tujuan peraturan yang berlaku. perusahaan.(COSO, 2013 dalam Ananta Budi (COSO, 2013 dalam Ananta Lasso \& Sutjipto Ngumar, 2016) Budi Lasso \& Sutjipto Ngumar, 2016)

1. Tingkat Sulitnya tugas

2. Struktur tugas

3. Banyaknya informasi yang tidak relevan

4. Adanya ambiguitas yang tinggi (William C Boynton, 2010 dalam Surtikanti \& Innes Sunarya, 2014)
\end{abstract}

\begin{tabular}{ll}
\hline Kompleksitas Tugas & Kompleksitas tugas merupakan tugas yang \\
(X3) & tidak terstruktur, sulit untuk dipahami, \\
& ambigu dan terkait satu sama lain.(William \\
& C Boynton, 2010:54 dalam Surtikanti \& \\
& Innes Sunarya, 2014:3)
\end{tabular}

\begin{tabular}{ll}
\hline Budaya Organisasi & Budaya organisasi merupakan kebiasaan- 1 . Involvement (keterlibatan) \\
(X4) & kebiasaan yang terjadi dalam hirarki organisasi 2. Consistency (konsistensi) \\
& yang mewakili norma-norma perilaku dan 3. Adaptability (adaptabilitas) \\
& diikuti oleh para anggota dalam organisasi, 4. Mission (misi). \\
& maka budaya organisasi akan memberikan (Denison, 1990 dalam Dewa \\
& suasana psikologis bagi semua anggota, Made \& Ida Bagus, 2016) \\
& bagaimana mereka bekerja, bagaimana \\
& berhubungan dengan atasan maupun rekan \\
& sekerja dan bagaimana menyelesaikan \\
& masalah merupakan wujud budaya yang khas \\
& bagi setiap organisasi.(Yamin, 2014 dalam \\
& Dewa Made \& Ida Bagus, 2016) \\
\end{tabular}


Tabel 2

Hasil Uji Validitas

\begin{tabular}{|c|c|c|c|c|}
\hline No & Indikator & rhitung & $\mathbf{r}$ tabel & Keterangan \\
\hline \multicolumn{5}{|c|}{ Kinerja karyawan } \\
\hline 1 & Y 1.1 & 0,939 & 0,2940 & Valid \\
\hline 2 & Y 1.2 & 0,935 & 0,2940 & Valid \\
\hline 3 & Y 1.3 & 0,802 & 0,2940 & Valid \\
\hline 4 & Y 1.4 & 0,913 & 0,2940 & Valid \\
\hline 5 & Y 1.5 & 0,936 & 0,2940 & Valid \\
\hline \multicolumn{5}{|c|}{ Sistem informasi akuntansi } \\
\hline 1 & X 1.1 & 0,844 & 0,2940 & Valid \\
\hline 2 & $\mathrm{X} 1.2$ & 0,901 & 0,2940 & Valid \\
\hline 3 & $\mathrm{X} 1.3$ & 0,965 & 0,2940 & Valid \\
\hline 4 & X 1.4 & 0,968 & 0,2940 & Valid \\
\hline 5 & X 1.5 & 0,970 & 0,2940 & Valid \\
\hline 6 & X 1.6 & 0,923 & 0,2940 & Valid \\
\hline \multicolumn{5}{|c|}{ Sistem pengendalian internal } \\
\hline 1 & $\mathrm{X} 2.1$ & 0,972 & 0,2940 & Valid \\
\hline 2 & $\mathrm{X} 2.2$ & 0,975 & 0,2940 & Valid \\
\hline 3 & $\mathrm{X}_{2.3}$ & 0.974 & 0,2940 & Valid \\
\hline \multicolumn{5}{|c|}{ Kompleksitas tugas } \\
\hline 1 & $\mathrm{X} 3.1$ & 0,882 & 0,2940 & Valid \\
\hline 2 & X 3.2 & 0,955 & 0,2940 & Valid \\
\hline 3 & X3.3 & 0,950 & 0,2940 & Valid \\
\hline 4 & X3.4 & 0,921 & 0,2940 & Valid \\
\hline \multicolumn{5}{|c|}{ Budaya organisasi } \\
\hline 1 & X 4.1 & 0,805 & 0,2940 & Valid \\
\hline 2 & $\mathrm{X} 4.2$ & 0,942 & 0,2940 & Valid \\
\hline 3 & $\mathrm{X} 4.3$ & 0,889 & 0,2940 & Valid \\
\hline 4 & X 4.4 & 0,872 & 0,2940 & Valid \\
\hline
\end{tabular}

Sumber : Data diolah, 2018

\section{Tabel 3}

Hasil Uji Reliabilitas

\begin{tabular}{llccc}
\hline No & Variabel & NilaiCronbach's alpha & Nilai Standar & Keterangan \\
\hline 1 & Kinerja karyawan $(\mathrm{Y})$ & 0,942 & 0,60 & Reliabel \\
2 & Sistem informasi akuntansi $\left(\mathrm{X}_{1}\right)$ & 0,968 & 0,60 & Reliabel \\
3 & Sistem pengendalian internal $\left(\mathrm{X}_{2}\right)$ & 0,972 & 0,60 & Reliabel \\
4 & Kompleksitas tugas $\left(\mathrm{X}_{3}\right)$ & 0,946 & 0,60 & Reliabel \\
5 & Budaya organisasi $\left(\mathrm{X}_{4}\right)$ & 0,898 & 0,60 & Reliabel \\
\hline
\end{tabular}

Sumber : Data diolah, 2018

Tabel 4

Analisis Regresi Linier Berganda

Coefficients $^{\mathrm{a}}$

\begin{tabular}{|c|c|c|c|c|c|c|c|}
\hline \multirow[t]{2}{*}{ Model } & \multicolumn{2}{|c|}{$\begin{array}{c}\text { Unstandardized } \\
\text { Coefficients }\end{array}$} & \multirow{2}{*}{$\begin{array}{l}\text { Standardized } \\
\text { Coefficients } \\
\text { Beta }\end{array}$} & \multirow[t]{2}{*}{$\mathrm{t}$} & \multirow[t]{2}{*}{ Sig. } & \multicolumn{2}{|c|}{$\begin{array}{c}\text { Collinearity } \\
\text { Statistics }\end{array}$} \\
\hline & $\mathrm{B}$ & Std.Error & & & & Tolerance & VIF \\
\hline 1 (Constant) & $-6,469$ & 2,491 & &,- 2596 & ,013 & & \\
\hline Sistem Informasi Akuntansi &, 163 & 085 &, 204 & 1,912 &, 063 &, 596 & 1,677 \\
\hline Sistem PengendalianInternal & ,312 & , 108 &, 248 & 2,895 &, 006 &, 927 & 1,079 \\
\hline Kompleksitas Tugas & , 494 & 143 &, 370 & 3,445 &, 001 &, 590 & 1,696 \\
\hline Budaya Organisasi & 650 &, 115 & ,388 & 4,185 &, 000 & ,792 & 1,263 \\
\hline
\end{tabular}

a. Dependent Variable: Kinerja Karyawan

Sumber : Data diolah, 2018 
sebesar 0,312 atau 31,2\%.

4. B3 (nilai koefisien regresi $\mathrm{X}_{3}$ ) sebesar 0,494 mempunyai artikoefisien regresi kompleksitas tugas $\left(\mathrm{X}_{3}\right)$ bernilai positif yang berarti bahwa akan meningkatkan kinerja karyawan sebesar 0,494 atau $49,4 \%$.

5. B4 (nilai koefisien regresi $X_{4}$ ) sebesar 0,650 mempunyai arti koefisien regresi budaya organisasi $\left(\mathrm{X}_{4}\right)$ bernilai positif yang berarti bahwa akan meningkatkan kinerja karyawan sebesar 0,650 atau $65,0 \%$.

Pengaruh Sistem Informasi Akuntansi Terhadap Kinerja Karyawan. Berdasarkan hasil uji penelitian secara parsial (Uji T), dapat diketahui bahwa nilait untuk sistem informasi akuntansi $\left(\mathrm{X}_{1}\right)$ terhadap kinerja karyawan (Y) sebesar 1,912 mempunyai pengaruh positif yang berarti bahwa semakin baik sistem informasi akuntansi, dapat dikatakan semakin meningkatkan kinerja karyawan. Sistem informasi akuntansi memiliki nilai Coefficient yang menunjukkan hasil significantsi sebesar 0,063, dimana nilai tersebut lebih kecil dari nilai alpha 0,050, Hal ini berarti bahwa hasil analisis dan pengujian hipotesis penelitian ini, diketahui bahwa adanya pengaruh yang signifikan antara variabel sistem informasi akuntansi $\left(\mathrm{X}_{1}\right)$ terhadap kinerja karyawan(Y).

Penelitian ini didukung oleh penelitian Achmad Budion, Azis Fathoni, \& Maria M Minarsih (2016) yang menyimpulkan bahwa Pengendalian Internal berpengaruh positif dan signifikan terhadap Kinerja Pegawai.

\section{Kompleksitas Tugas Terhadap Kinerja} Karyawan. Berdasarkan hasil uji penelitian secara parsial(Uji T), dapat diketahui bahwa nilait untuk variabel kompleksitas tugas $\left(\mathrm{X}_{3}\right)$ terhadap kinerja karyawan (Y) sebesar 3,445 mempunyai pengaruh positif yang berarti bahwa semakin baik kompleksitas tugas yang terdapat di perusahaan, maka semakin meningkatkan kinerja karyawan. Kompleksitas tugas memiliki nilai Coefficient yang menunjukkan hasil signifikansi sebesar 0,001, dimana nilai tersebut lebih kecil dari nilai alpha 0,050, Hal ini berarti bahwa hasil analisis dan pengujian hipotesis penelitian ini, diketahui bahwa adanya pengaruh yang signifikan antara variabel kompleksitas tugas $\left(\mathrm{X}_{3}\right)$ terhadap kinerja karyawan (Y).
Penelitian ini didukung oleh penelitian Eny Parjanti, Kartika Hendra \& Siti Nurlela (2014) yang menyimpulkan bahwa task complexity significant influence on employee performance ( kompleksitas tugas berpengaruh positif dan signifikan terhadap kinerja pegawai ).

Pengaruh Budaya Organisasi Terhadap Kinerja Karyawan. Berdasarkan hasil uji penelitian secara parsial (Uji T) dapat diketahui bahwa nilai t untuk variabel budaya organisasi $\left(\mathrm{X}_{4}\right)$ terhadap kinerja karyawan (Y) sebesar 4,185 mempunyai pengaruh positif yang berarti bahwa semakin baik budaya organisasi yang terdapat di perusahaan, maka semakin meningkatkan kinerja para karyawan yang ada. Budaya organisasi memiliki nilai Coefficient yang menunjukkan hasil signifikansi sebesar 0,000, dimana nilai tersebut lebih kecil dari nilai alpha 0,050 , Hal ini berarti bahwa hasil analisis dan pengujian hipotesis penelitian ini, diketahui bahwa adanya pengaruh yang signifikan antara variabel budaya organisasi $\left(\mathrm{X}_{4}\right)$ terhadap kinerja karyawan (Y).

Penelitian ini didukung oleh penelitian Achmad Budion, Azis Fathoni, \& Maria M Minarsih pada (2016) yang menyimpulkan bahwa Budaya Organisasi berpengaruh positif dan signifikan terhadap Kinerja Pegawai.

\section{KESIMPULAN}

Simpulan. Berdasarkan analisis dan pembahasan yang sudah di lakukan, didapat kesimpulan sebagai berikut :

1. Sistem Informasi Akuntansi $\left(X_{1}\right)$ mempunyai pengaruh positif dan signifikan terhadap kinerja karyawan (Y).

2. Sistem Pengendalian Internal $\left(\mathrm{X}_{2}\right)$ mempunyai pengaruh positif dan signifikan terhadap kinerja karyawan (Y).

3. Kompleksitas Tugas $\left(\mathrm{X}_{3}\right)$ mempunyai pengaruh positif dan signifikan terhadap kinerja karyawan (Y).

4. Pengaruh Budaya Organisasi $\left(\mathrm{X}_{4}\right)$ mempunyai pengaruh positif dan signifikan terhadap kinerja karyawan $(\mathrm{Y})$

5. Sistem informasi akuntansi, sistem pengendalian intern, kompleksitas tugas, budaya organisasi secara bersama-sama berpengaruh terhadap 
kinerja karyawan.

Saran. Adapun saran yang dapat diberikan dari hasil penelitian ini adalah sebagai berikut:

1. Keterbatasan hanya mengambil satu objek, untuk itu sebaiknya objek diperluas lebih dari satu perusahaan sehingga dapat di jadikan pembanding agar dapat mencerminkan kondisi secara keseluruhan.

2. Variabel kinerja karyawan sebesar $29,9 \%$ diterangkan oleh variabel lain yang tidak diajukan dalam penelitian ini, sehingga untuk penelitian selanjutnya perlu di tambah variabel lain.

\section{DAFTAR PUSTAKA}

Achmad Budion, Azis Fathoni, \& Maria M Minarsih. 2016. Pengaruh Good Governace, Pengendalian Intern, dan Budaya Organisasi terhadap Kinerja Pegawai Kantor Keuangan Kodam IV Diponegoro yang Berkedudukan di Semarang.

Alfabeta. Suwarsih, Asri. 2010. Pengaruh Budaya Organisasi, Gaya Kepemimpinan dan Pengendalian Intern Terhadap Penerapan Good Governance Serta Dampaknya Pada Kinerja Manajerial ( Studi pada Universitas Jendral Soedirman)". Skripsi

Ananta Budi Lasso \& Sutjipto Ngumar. 2016. Pengaruh Pengendalian Intern terhadap Kinerja Karyawan Bagian Produksi PT. Brother Silver.
Eny Parjanti, Kartika Hendra \& Siti Nurlela .2014. Pengaruh Sistem Informasi Akuntansi, Gaya Kepemimpinan, dan Kompleksitas Tugas terhadap Kinerja Karyawan.

Fahmi Rizaldi \& Bambang Suryono. 2015. Pengaruh Sistem Informasi Akuntansi terhadap Kinerja Karyawan CV Teguh Karya Utama Surabaya.

Ghozali, I. 2011. Aplikasi Analisis Multivariate Dengan Program SPSS. Cetakan Kelima. Badan Penerbit Universitas Diponegoro Semarang.

Ika Listiana. 2017. Pengaruh Sistem Informasi Akuntansi dan Sistem Pengendalian Internal terhadap Kinerja Karyawan Studi Kasus pada KSPPS Bina Insan Mandiri.

Jogiyanto. 2010. "Pedoman Survei Kuesioner". BFFE: Yogyakarta.

Mulyadi, 2008. Sistem Akuntansi. Edisi Ketiga. Cetakan Keempat. Penerbit Salemba Empat. Jakarta

Porwani, Sri. 2010. Pengaruh Budaya Organisasi Terhadap Kinerja Karyawan Pada PT. Tambang Batubara Bukit Asam (PERSERO) Tanjung Enim. Orasi Bisnis Edisi ke-2. Vol. 11 ; No. 2.

Santoso, Singgih. 2007. Statistik Deskriptif: Konsep dan Aplikasi dengan Microsoft Exel dan SPSS. Yogyakarta: ANDI.

Sugiyono. 2012. Metode Penelitian Kuantitatif Kualitatif dan R\&D. Bandung: 